\title{
Article
}

\section{Why are Background Telephone Conversations Distracting?}

Marsh, John Everett, Ljung, Robert, Jahncke, Helena, MacCutcheon, Douglas, Pausch, Florian, Ball, Linden and Vachon, François

Available at https://clok.uclan.ac.uk/21771/

Marsh, John Everett orcid iconORCID: 0000-0002-9494-1287, Ljung, Robert, Jahncke, Helena, MacCutcheon, Douglas, Pausch, Florian, Ball, Linden orcid iconORCID: 0000-0002-5099-0124 and Vachon, François (2018) Why are Background Telephone Conversations Distracting? Journal of Experimental Psychology: Applied, 24 (2). pp. 222-235. ISSN 1076-898X

It is advisable to refer to the publisher's version if you intend to cite from the work. http://dx.doi.org/10.1037/xap0000170

For more information about UCLan's research in this area go to http://www.uclan.ac.uk/researchgroups/ and search for < name of research Group>.

For information about Research generally at UCLan please go to http://www.uclan.ac.uk/research/

All outputs in CLoK are protected by Intellectual Property Rights law, including Copyright law. Copyright, IPR and Moral Rights for the works on this site are retained by the individual authors and/or other copyright owners. Terms and conditions for use of this material are defined in the policies page.

\section{CLoK}

Central Lancashire online Knowledge www.clok.uclan.ac.uk

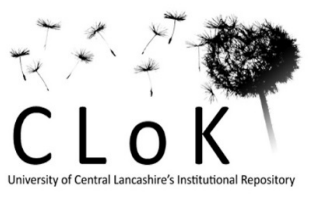



Experimental Psychology: Applied. The copyedited article may differ from this manuscript version. The details of the published article are as follows:

Marsh, J. E., Ljung, R., Jahncke, H., MacCutcheon, D., Pausch, F., Ball, L. J., \& Vachon, F. (in press). Why are background telephone conversations distracting? Journal of Experimental Psychology: Applied.

Why are Background Telephone Conversations Distracting?

John E. Marsh ${ }^{1,2}$, Robert Ljung ${ }^{1}$, Helena Jahncke ${ }^{1}$, Douglas MacCutcheon ${ }^{1}$, Florian Pausch ${ }^{1,4}$, Linden J. Ball ${ }^{2}$ and François Vachon ${ }^{1,5}$

${ }^{1}$ Department of Building, Energy and Environmental Engineering, University of Gävle, Gävle, Sweden

${ }^{2}$ School of Psychology, University of Central Lancashire, Preston, UK

${ }^{3}$ Centre for Musculoskeletal Research, Department of Occupational and Public Health Sciences, Faculty of Health and Occupational Studies, University of Gävle, Sweden ${ }^{4}$ Institute of Technical Acoustics, RWTH Aachen University, Aachen, Germany ${ }^{5}$ École de psychologie, Université Laval, Québec, Canada

RUNNING HEAD: Telephone Distraction

Correspondence: John E. Marsh, School of Psychology, Darwin Building, University of Central Lancashire, Preston, Lancashire, United Kingdom, PR1 2HE.

Phone (+44) 1772 893754, Fax (+44) 1772892925

E-mail: JEMarsh@uclan.ac.uk 


\begin{abstract}
Telephone conversation is ubiquitous within the office setting. Overhearing a telephone conversation — whereby only one of the two speakers is heard - is subjectively more annoying and objectively more distracting than overhearing a full conversation. The present study sought to determine whether this "halfalogue" effect is attributable to unexpected offsets and onsets within the background speech (acoustic unexpectedness) or to the tendency to predict the unheard part of the conversation (semantic [un]predictability), and whether these effects can be shielded against through top-down cognitive control. In Experiment 1, participants performed an office-related task in quiet or in the presence of halfalogue and dialogue background speech. Irrelevant speech was either meaningful or meaningless speech. The halfalogue effect was only present for the meaningful speech condition. Experiment 2 addressed whether higher task-engagement could shield against the halfalogue effect by manipulating the font of the to-be-read material. While the halfalogue effect was found with an easy-to-read font (fluent text), the use of a difficult-to-read font (disfluent text) eliminated the effect. The halfalogue effect is thus attributable to the semantic (un)predictability, not the acoustic unexpectedness, of background telephone conversation and can be prevented by simple means such as increasing the level of engagement required by the focal task.
\end{abstract}

Keywords: Office noise, distraction, halfalogue, predictability, task-engagement, disfluency.

\title{
Public Significance Statement
}

Conversing via telephony is ubiquitous in office settings and overhearing one half of a conversation is detrimental to ongoing task performance. This "halfalogue effect" only arises if one can understand the content of the speech and can be prevented by increasing the level of engagement (or concentration) required by the ongoing task. 
Background noise is a fundamental problem within society. Decreased productivity

(Mak \& Lui, 2012; Young \& Berry, 1979), motivation (Evans \& Stecker, 2004), satisfaction (Sundstrom, Town, Rice, Osborn, \& Brill, 1994) and well-being (Babisch, 2003; Evans \& Johnson, 2000; Jahncke \& Halin, 2012) associated with noise can confer substantial costs for organizations (Jahncke, Hongisto, \& Virjonen, 2013). In an extensive survey, 8 in 10 office workers reported that they are regularly disrupted by office noise and respondents claimed that their productivity drops by $66 \%$ in a noisy environment (Avanta Serviced Office Group, 2015). Despite the wealth of evidence suggesting that noisy environments are damaging, the open-plan office solution is often used (Toivanen, 2015). Within the office setting, background conversations/gossip and loud phone voices are rated as the most annoying office noises (Avanta Serviced Office Group, 2015). The ubiquity of telephone use within the office and in public spaces means that individuals are unavoidably exposed to background speech. Active engagement in telephone conversation is known to have adverse consequences on cognition: Speaking on a telephone reduces driver accuracy (Strayer \& Johnston, 2001) and has negative consequences for pedestrian safety (Stavrinos, Byington, \& Schwebel, 2009). However, limited research has considered the degree of distraction a co-worker experiences from another's telephone conversation while performing a task. What little evidence there is suggests that individuals perceive other's telephone conversations (or halfalogues; halves of conversations such as a cell-phone conversation whereby only one speaker can be heard) as subjectively more noticeable and intrusive than dialogues (e.g., both sides of the conversation; Monk, Carroll, Parker, \& Blythe, 2004; Monk, Fellas, \& Ley, 2004). Moreover, several objective measures have reinforced these subjective ratings: Cognitive performance is differentially affected by halfalogues and dialogues. For example, Emberson, Lupyan, Goldstein, and Spivey (2010; see also Galván, Vessal, \& Golley, 2013) found that ignoring a 
halfalogue as compared with a dialogue disrupted performance on a visual monitoring (tracking) task and a choice reaction task.

Given the considerable amount of exposure to other's telephone conversations within the office setting, it is important to understand the underpinnings of the halfalogue effect with the end-goal of armoring the employee or companies with measures that can shield against such distraction (cf. Halin, Marsh, Haga, Holmgren, \& Sörqvist, 2014; Halin, Marsh, Hellman, Hellström, \& Sörqvist, 2014). However, to date the mechanism involved in producing the halfalogue effect is poorly understood. This is because the characteristics of the background speech underpinning the effect have received scant scrutiny (cf. Norman \& Bennett, 2014). In order to address this shortfall, we manipulate the properties of background speech to unveil the mechanism of distraction responsible for producing the halfalogue effect. Moreover, to increase the applied relevance of the study, we investigate the halfalogue effect in the context of a realistic office-based task (Jahncke \& Halin, 2012). An additional concern of the current study is to find a means by which the disruption of cognitive performance produced by a halfalogue can be ameliorated. Since increasing task-engagement through displaying studied material in a disfluent font reduces the disruption of proofreading and reading comprehension by irrelevant speech (Halin, 2016; Halin, Marsh, Haga et al., 2014, Halin, Marsh, Hellman et al., 2014), we sought to investigate whether such a manipulation could also shield against the halfalogue effect. We note that there is considerable applied value in identifying ways to mitigate against the negative consequences of the halfalogue effect in relation to cognitive task performance. For example, if factors that promote more steadfast task engagement (e.g., disfluent information presentation) can be appropriately attuned to the ecology of a particular office setting then useful increases in work productivity might be achieved. 
The key theoretical assumption motivating our reported research is that the halfalogue

effect is a variety of auditory attentional capture whereby attention is momentarily disengaged from the focal task due to the presence of an auditory stimulus (Hughes, Vachon, \& Jones, 2007; Marsh et al., 2017; Monk, Fellas, \& Ley, 2004; Vachon, Labonté, \& Marsh, 2017). Attentional capture can sometimes be specific, occurring when the particular content of the sound causes its attentional-diversion potency, such as when a sound is of interest to a given individual (e.g., the sound of water running for a thirsty person). Alternatively, attentional capture can be aspecific, as occurs when a sound captures attention because of the context in which it occurs, such as the sudden onset of speech following a period of quiet (see Eimer, Nattkemper, Schröger, \& Prinz, 1996).

According to this aforementioned theoretical analysis, the attentional-diverting power of specific attentional capture is due to the content of the stimulus itself. In contrast, for aspecific attentional capture it is nothing "specific" about the stimulus itself that endows the stimulus with its attention capturing power. Rather, what is relevant is purely the context (e.g., silence) within which the stimulus (e.g., speech) is presented. However, because a halfalogue is unpredictable due to its flow (the presence of unexpected offsets and onsets within the sound) and its semantic content (it is difficult to predict what will be said), then either its semantic (un)predictability (i.e., specific attentional capture) or its acoustic unexpectedness (i.e., aspecific attentional capture) could be the agent responsible for capturing attention away from the focal task. The reported research set out to arbitrate between these alternative theoretical accounts of the halfalogue effect.

\section{Semantic (Un)predictability Hypothesis/Need to Listen}

From the standpoint of the semantic (un)predictability hypothesis, overhearing half of a conversation could impair performance on a focal task because attention is directed automatically and involuntarily toward the sound due to an individual's "need-to-listen" in 
order for them to be able to predict and understand the semantic content of the inaudible half of the conversation (Monk, Fellas, \& Ley, 2004; Norman \& Bennett, 2014). Indeed, Monk and colleagues (2004) proposed that individuals possess a tendency to complete information that is incomplete because the cognitive system desires to comprehend it, and this drives the specific attentional capture. This notion of involuntary eavesdropping receives support from the finding that participants recognize proportionally more words from a halfalogue in comparison to a complete conversation when given a surprise recognition test (Galván et al., 2013). Galván and colleagues (2013) found that this better memory for the content of the halfalogue speech occurred in the absence of a breakdown in performance on an anagram task that was earlier accompanied by the halfalogue or full conversational speech. Unfortunately, this study is not useful in helping one understand the underpinnings of the halfalogue effect on task performance since no behavioral disruption was observed.

Moreover, Norman and Bennett (2014) compared full conversation or halfalogue in participants' mother tongue with speech from a language foreign to the participants (and hence meaningless). In comparison to the other conversations, participants reported that the meaningful halfalogue was more annoying and that they found themselves listening to it more. Since the meaningless halfalogue was also acoustically unpredictable, but was not rated as more annoying or intrusive than the meaningless full conversational speech, the authors argued that semantic unpredictability produces the halfalogue effect. However, despite the demonstrable (and reliable) individual differences in distractibility (Ellermeier \& Zimmer,1997; Hughes, Hurlstone, Marsh, Vachon, \& Jones, 2013; Marsh, Vachon, \& Sörqvist, 2017; Sörqvist, 2010), subjective data (e.g., annoyance ratings) and objective data (behavioral distraction) are typically only weakly associated (Beaman, 2005; Ellermeier \& Zimmer, 1997; Jiang, Liebl, Leistner, \& Yang, 2012; Park, Kohlrausch, \& van Leest, 2013; Perham, Banbury, \& Jones, 2007; Schlittmeier \& Hellbrück, 2009; Schlittmeier, Hellbrück, 
Thaden, \& Vorländer, 2008): participants' subjective self-assessment of how distracted they are from background sound, seldom maps on to how objectively distracted they are from the same sound, even if they have a preference for one sound over another (Perham \& Sykora, 2012). Therefore, little can be determined from this study about whether the behavioral distraction caused by the halfalogue is an effect attributable to semantic unpredictability.

\section{Acoustic Unexpectedness Hypothesis}

Although previous findings suggest that the halfalogue produces disruption due to its semantic content, there is a substantial literature demonstrating that the unpredictability of sound produces distraction via aspecific attentional capture. According to the acoustic unexpectedness account (Parmentier, Elsley, Andrés, \& Barceló, 2011; Vachon, Hughes, \& Jones, 2012; Winkler, Denham, \& Nelken, 2009), disengagement of attention from the focal task can occur due to rudimentary processing of the acoustic features of the ignored speech (e.g., Hughes, Vachon, \& Jones, 2005; Schröger, 1997). For example, unexpected changes in the pattern of auditory stimulation in terms of the timing of the unattended items (Hughes et al., 2005) and their acoustic characteristics (e.g., the " $\mathrm{m}$ " in the irrelevant sequence "k k k k k k k m k k") impairs short-term memory for a sequence of visually-presented items (Hughes, Vachon, \& Jones, 2007; Vachon et al., 2012). The disruption produced by the unexpected item, or deviant, is due to aspecific attentional capture since the deviant is such because it violates rules concerning the context within which it is presented (e.g., repeated presentation of the same auditory token). Consistent with the acoustic unexpectedness view, intermittent and hence unpredictable noise is typically more disruptive than continuous noise (Kjellberg, Landstrom, Tesarz, Soderberg, \& Akerlund, 1996; Szalma \& Hancock, 2011). For example, intermittent background teletype sound has been shown to impair the detection of contextual (grammatical) errors on a proofreading task (Weinstein, 1974). 
The relevance here is that a halfalogue is also acoustically unpredictable: In the context of a full conversation, individuals are speaking continuously as turn-taking shifts between the speakers. However, for a halfalogue the relatively constant auditory stream becomes interrupted by silent periods of variable duration. The unexpected onset and offset of the voice within the audible side of a phone conversation could produce a violation of the expectancy of auditory events within the sound stream, causing aspecific attentional capture: Attention might be diverted from the focal task toward the sound when unexpected periods of quiet occur within a context of continuous speech, resulting in impoverished recall of visual events. Moreover, when attention is captured by sound, the content of the sound tends to be processed thereby potentially producing greater disruption (e.g., Escera, Yago, Corral, Corbera, \& Nuñez, 2003; Marsh, Röer, Bell, \& Buchner, 2014; Parmentier, Elford, Escera, Andrés, \& San Miguel, 2008; Parmentier \& Kefauver, 2015).

Although it would appear from the aforementioned studies (e.g., Monk, Fellas, \& Ley, 2004; Norman \& Bennett, 2014) that semantic content may be key for the appearance of the halfalogue effect (Emberson et al., 2010), it is unknown whether this is because the semantic content is unpredictable, or whether the acoustic unpredictability of the onset of the half conversation captures attention and semantic processing follows thereafter (e.g., Parmentier $\&$ Kefauver, 2015). Thus, there is no clear evidence that the semantic content of the background speech can directly disrupt the focal task: it may do so as a mere by-product of auditory attentional capture. We also note that Emberson and colleagues (2010) report that low-pass filtering of the halfalogue, which made the speech incomprehensible, removed its disruptive effect. However, the authors did not report the exact details of the filtering process and therefore it is plausible that the fundamental frequencies that remained led to reductions in the sharpness of the onsets and offsets of speech that could attenuate the potency with which they capture attention due to their acoustic unexpectedness. 


\section{Aims of the Current Experiments}

We report two experiments that were undertaken to investigate the halfalogue effect: one that investigated the theoretical underpinnings of the effect and another that addressed its preventability so as to advance applied objectives. More specifically, the first aim of this research was to tease apart the acoustic unexpectedness account from the semantic (un)predictability account. To this end, in Experiment 1 we compared the effects of normal speech with that of spectrally-rotated speech in the context of both a halfalogue and a dialogue. Spectrally-rotated speech is not intelligible. It sounds like an "alien" language but it possesses very similar temporal and spectral complexity to normal speech. It also preserves the intonation and timing of normal speech. The acoustic complexity of spectrally-rotated speech and normal speech is therefore well-matched (Scott, Rosen, Beaman, Davis, \& Wise, 2009). Thus, the principal difference between spectrally-rotated speech and normal speech is its meaningfulness.

Importantly, the spectrally-rotated halfalogue and the normal halfalogue are matched in terms of their acoustic — and temporal — unexpectedness. Inclusion of the spectrally-rotated speech condition is necessary to determine whether the disruptive effect of the halfalogue is due to acoustic unexpectedness or semantic (un)predictability. If the halfalogue is more disruptive than the dialogue for both normal speech and spectrally-rotated speech then the disruptive effect of the halfalogue must be attributable to acoustic unexpectedness (e.g., Hughes et al., 2005, 2007; Vachon et al., 2012). However, if the halfalogue is only more disruptive than the dialogue for the normal speech condition, then the semantic (un)predictability account would prevail (Emberson et al., 2010; Monk, Fellas, \& Ley, 2004; Norman \& Bennett, 2014).

A second aim of the present research was to address whether the halfalogue effect can be prevented. Several studies have demonstrated that presenting memoranda in a disfluent 
font shields against distraction in paradigms that are theoretically-oriented (Hughes et al.,

2013; Marsh, Sörqvist, \& Hughes, 2015), and for tasks that hold applied relevance for office and scholastic environments such as proofreading and reading comprehension (Faber, Mills, Kopp, \& D’mello, 2017; Halin, 2016; Halin, Marsh, Haga et al., 2014; Halin, Marsh, Hellman et al., 2014). A typical explanation of these findings is that the perceptually disfluent font acts as a metacognitive cue that the task is difficult (e.g., Bjork, Dunlosky, \& Kornell, 2013; Thompson, 2010), with the metacognitive system instigating a compensatory upward shift in task-engagement (or concentration) such that an individual can maintain a desired performance level (Sörqvist \& Marsh, 2015; Eggemeir, Crabtree, \& LaPointe, 1983; see also Ball, Threadgold, Solowiej, \& Marsh, 2018). It is suggested that the greater task-engagement that the perceptually disfluent font demands, leads to a more steadfast locus of attention (e.g., unexpected irrelevant stimuli are less likely to capture attention away from the focal task) and reduces processing (and therefore awareness) of the surrounding environment (Sörqvist \& Marsh, 2015). This account is similar to that offered by Forster and Lavie (2009), who found that undertaking visual search tasks with higher perceptual load (e.g., when the target is embedded within heterogeneous compared to homogeneous distractors, which the authors proposed led to greater task-engagement), reduced participants reports of internal distractions (i.e., mind wandering). In Experiment 2, then, we sought to determine whether making task material more difficult to read, and thus perceptually disfluent, reduces the halfalogue effect, like it does for other disruptive effects produced by background sound on task performance (e.g., Halin, Marsh, Haga et al., 2014; Halin, Marsh, Hellman et al., 2014).

A further aim of the study was to examine the underpinnings of the halfalogue effect, and its susceptibility to modulation by the perceptual disfluency of the task material, in the context of a realistic, applied task of relevance to an office setting, that is, a search task that required participants to retrieve information from an organized table based upon search 
criteria (Jahncke \& Halin, 2012). The task was designed to be representative of typical tasks

used within the open-plan offices of call centers and other service information providers, wherein employees work within close proximity to one another and are exposed to others' telephone conversations (Jahncke \& Halin, 2012). Within these types of setting, employees must search for relevant information from tables in response to enquiries (cf. Perham \& Banbury, 2012). Examining the potential impact of a meaningful halfalogue on task performance is particularly important since the ubiquity of background telephony within the office environment may impact on productivity (Mak \& Lui, 2012; Young \& Berry, 1979) and have adverse effects on the well-being of employees (Babisch, 2003; Evans \& Johnson, 2000).

\section{Experiment 1}

\section{Method}

Participants. Seventy-six undergraduate students at the University of Gävle, aged between 17 and 23 years $(M=18.5, S D=0.82)$ were recruited via opportunity sample. All participants spoke Swedish as their first language and reported normal (or corrected-tonormal) vision and normal hearing. Participants were randomly, and equally, assigned to one of the between-participants groups: normal speech or rotated speech. Thus, thirty-eight participants were assigned to the normal speech condition and thirty-eight were assigned to the rotated speech condition. This study was approved by the Uppsala regional ethical review board (REPN 2011/338).

Noise conditions. Three sound conditions were used. These comprised quiet, a halfalogue (one side of a phone conversation between a male and a female speaker), or a dialogue (two sides of the exact same phone conversation). The phone conversation lasted for approximately eight minutes and the onset of this conversation coincided with the onset of the office-based task. The topic of the phone conversations concerned everyday things such 
as health, what happened during the weekend, family, leisure activities and upcoming events at work. The conversers spoke in Swedish and this was digitally recorded by the computer with a sE Electronics sE2200A condenser mic and a Creative E-MU0404 USB sound card. The conversation was sampled at $44.1 \mathrm{kHz}$ using Steinberg Cubase 5 software and equalized with a high-pass filter. Audio recordings were made in quiet rooms (30-34 dBA).

Meaningless speech was created by spectrally inverting the whole speech recording around $2 \mathrm{kHz}$ (as in Scott et al., 2009). Spectrally rotating this speech involves transforming the high-frequency energy into low-frequency energy and vice versa. Spectrally-rotated speech is approximately identical to normal speech (Scott et al., 2009). For example, variations in sound pressure level across time and the duration of pauses between words and sentences are fairly equal. However, rotated speech is meaningless because it is incomprehensible. Both normal speech and rotated speech were delivered by a Dell Latitude E6430 laptop PC and presented over stereo headphones at approximately $69 \mathrm{~dB}$ (LAeq) as measured with an artificial ear.

Focal task. The office-based task consisted of a paper-based version of the Search Task used by Jahncke and Halin (2012). In this task, participants had to search an organized table with information retrieved from Statistics Sweden (SCB). The table contained ten columns concerning price, location, area, year etc. Moreover, there were also twelve rows with information about occupation (four), and gender (female, male, total), followed by the allocation of mean salary and number of employees over four different years. The participants were asked to locate the cell containing the answer either by using one column (easy), two columns (medium), or more than two columns (difficult; see top panel of Figure 2). Therefore, the task requires that participants comprehend the contents of the table and search through it while updating and memorizing information according to the criterion of the target. Participants were required to answer as many questions as they could (18 questions in 
total). Six questions were presented at each level of difficulty (easy, medium, and hard). Each

experimental block consisted of 18 questions and the answer time was limited to eight minutes. The questions were arranged into six triplets and within each triplet the questions were presented in ascending order of difficulty. Although the questions were arranged into triplets there was no separation between each triplet on the page as equal row spaces were presented between each question. The dependent variable was the sum of problems correctly solved.

Design. The study employed a mixed design with one between-participants factor: Type of Speech (normal vs. rotated), and one within-participant factor: Sound Condition (quiet, halfalogue, and dialogue). The dependent variable was number of problems correctly solved.

Procedure. Participants were seated at a distance of approximately $60 \mathrm{~cm}$ from the PC monitor in a quiet testing cubicle. They were instructed to ignore any background sound, and to focus on completing the office-based task, as fast and as accurately as possible. Before they started, they received a booklet with the tasks, set in the order that they should solve them (previously randomized by the experimenters). A computer program displayed instructions concerning the search task to the participants. Participants were informed to turn a page in the booklet when they heard a beep sound over headphones. Participants pressed a start button to commence the experiment. As soon as they clicked on the start button a countdown of $5 \mathrm{~s}$ appeared on the screen. Thereafter a further text instruction was displayed informing the participants to ignore the sounds presented over headphones and to perform the search task presented in their booklet. During this, the auditory material for the respective condition, or silence was played back. At the end of each condition, a beep indicated to the participant that they should turn to the next page in the booklet and another countdown starting at $20 \mathrm{~s}$ appeared on the screen. When this expired the process was repeated until all 
three conditions were completed. Participants undertook one search task (comprising 18 questions; 6 easy, 6 medium and 6 difficult) in quiet, one against a background of halfalogue speech and one against a background of dialogue speech (the speech conditions comprised either normal or spectrally-rotated speech depending on which between-participants condition the participant was assigned). These noise conditions were counterbalanced by using a Latin Square. The whole procedure took about 25 minutes and the participants received a cinema ticket for their participation.

\section{Results}

Preliminary analysis including Order (of the sound conditions) revealed no main effect of Order nor any interactions with this factor. Thus it was omitted from the subsequent analysis. As can be seen in Figure 1, the halfalogue against the quiet and dialogue conditions depressed performance in the normal speech condition, but appeared to have little effect in the rotated speech condition. This was confirmed by a main effect of Sound Condition, $F(2$, $148)=5.57, M S E=6.64, p=.005, \eta^{2} \mathrm{p}=.070$. There was also a main effect of Type of Speech, $F(1,74)=4.74, M S E=25.50, p=.033, \eta_{p}^{2}=.060$. Crucially, the interaction between Sound Condition and Type of Speech was also significant, $F(2,148)=6.57, M S E=2.12, p=$ $.002, \eta^{2}=.082$. This interaction arose because, as illustrated in Figure 1, the effect of Sound Condition was significant with normal speech, $F(2,74)=15.27, M S E=5.15, p<.001, \eta^{2} \mathrm{p}=$ .292 , but not with rotated speech $(F<1)$. Further scrutiny of the impact of Sound Condition with normal speech revealed that problem solving performance was significantly impaired by halfalogues compared to dialogues or quiet $(p s<.001)$, whereas no difference was found between dialogues and quiet $(p=.476)$.

\section{Discussion}

The results of the experiment were unequivocal in providing support for the semantic (un)predictability account of the halfalogue effect. The halfalogue effect only manifested 
when the background speech material was meaningful. Given that both the meaningful and meaningless (rotated) halfalogue speech were equated in terms of their acoustic complexity and temporal unpredictability, then the observation that only the meaningful halfalogue produces impairment refutes the acoustic unexpectedness account of the halfalogue effect (cf. Hughes et al., 2005). That the halfalogue effect is dependent upon the presence of semantic properties within the sound demonstrates that it is a form of distraction that differs from that attributable to acoustic unexpectedness (Hughes et al., 2005, 2007; Vachon et al., 2012). The halfalogue effect cannot, therefore, be viewed as a form of deviation effect that is attributable to unpredictable occurrences of sound. Rather, it is a specific attentional capture effect (as opposed to an aspecific attentional capture effect), occurring due to the particular content of the sound rather than a violation of the acoustical context in which it occurred (such as the sudden onset of speech following quiet).

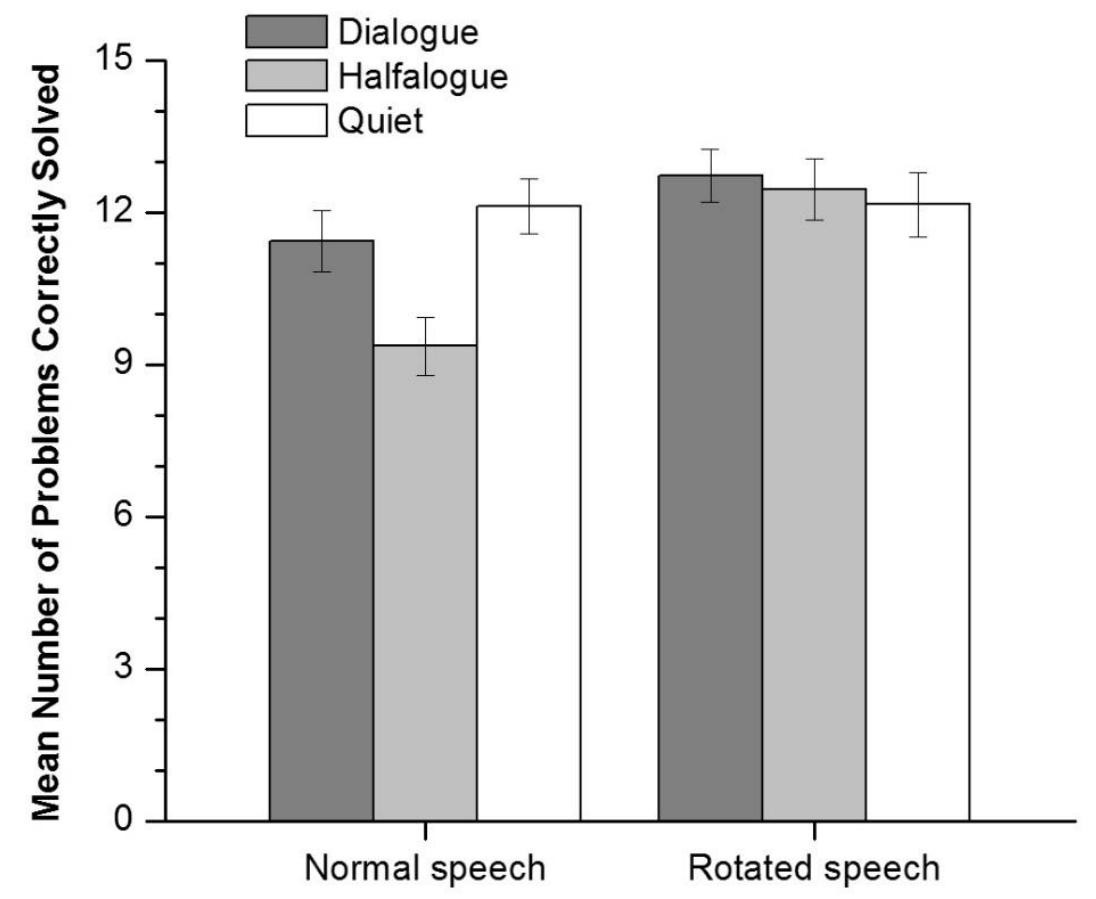

Figure 1. Mean number of problems correctly solved across the three sound conditions for normal and rotated speech. Error bars represent the standard error of the mean. 
Furthermore, the halfalogue effect cannot also be reconciled within the competition-

for-action view of semantic distraction. Here, distraction occurs when the semantic properties of the auditory background disrupt the ongoing processing of the focal task. Pronounced distraction occurs when the background speech conveys information that is relevant to the focal task material (Marsh, Hughes, \& Jones, 2008, 2009). If the task requirements involve processing the identity of semantically rich information, semantic distraction results. However, if the focus is on the retaining the order of that information the effect disappears (Marsh et al., 2008; Sörqvist, Marsh, \& Jahncke, 2010). Therefore, in the context of studies that demonstrate competition-for-action, distraction occurs not because there is semantic information within the task but precisely because this semantic information is being processed. In the current study, even though the meaningfulness of the sound was important for the halfalogue to produce disruption, the content of the sound was not related to the task at hand (as it requires to be in order to demonstrate a pronounced semantic form of competition-for-action; Marsh et al., 2008). Moreover, that the semantic content of the sound in the current study only produces distraction in the context of the halfalogue suggests that the semanticity of the background speech per se is not the most important component of speech in terms of its potency to disrupt focal task performance in this applied task setting. Therefore, the attentional capture effect demonstrated here is more consistent with the semantic-unpredictability—or need-to-listen—account (e.g., Monk, Fellas, \& Ley, 2004; Norman \& Bennet, 2014) than an acoustic unexpectedness account (e.g., Parmentier et al., 2011; Vachon et al., 2012; Winkler et al., 2009).

\section{Experiment 2}

The results of Experiment 1 suggest that the halfalogue effect is driven by attentional capture as opposed to competition-for-action (see Hughes, 2014, for a comparison of these two distinct mechanisms of auditory distraction). Such a distinction is key to finding ways to 
reduce the distractive power of halfalogues, which would have important applied benefits in

workplace environments where halfalogues are commonplace. Indeed, previous research demonstrates that the behavioral consequence of attentional capture-in terms of the disruption of focal task performance — can be tempered by top-down cognitive control. For example, reducing the perceptual discriminability of to-be-remembered material eliminates the disruption that an unexpected deviant sound confers on the ordered recall of sequences of visually-presented items (Hughes et al., 2013). It was argued in Hughes et al. (2013) that perceptual difficulty increased task-encoding load and eliminated the disruptive effect of the unexpected deviant sound by supporting an upward shift in focal task-engagement through a top-down mechanism (for a similar notion, see Buetti \& Lleras, 2016, and Faber et al., 2017). Consistent with this suggestion, presenting text in a disfluent (i.e., difficult-to-read) font reduces the disruption of proofreading and reading comprehension by the presence of taskirrelevant speech (Halin, 2016; Halin, Marsh, Haga et al., 2014; Halin, Marsh, Hellman et al., 2014). In the same vein, disfluent text has been shown to reduce mind wandering, a form of internal distraction, by "enhancing attention" on the focal task (Faber et al., 2017).

On the basis of our evidence from Experiment 1 that the halfalogue effect constitutes an attentional capture variety of distraction, it is possible that this particular effect can likewise be tempered by top-down cognitive control. That is, distraction by a halfalogue may be shielded against through the manipulation of factors that promote focal task-engagement (cf. Hughes et al., 2013; Halin, Marsh, Haga et al., 2014; Halin, Marsh, Hellman et al., 2014; see also Halin, 2016, and Marsh et al., 2015). Therefore, providing that an individual is exposed to a telephone conversation while undertaking a visually-based task, a simple manipulation of font disfluency — to increase task-engagement—may shield against the distracting effects of the halfalogue. This possibility is explored in Experiment 2 whereby one group of participants undertook the search task with the text displayed in a fluent font (low 
task-engagement; Times New Roman) and another group undertook the search task with the text displayed in a disfluent font (high task-engagement; Haettenschweiler).

\section{Method}

Participants. Seventy-six undergraduate students at the University of Gävle, aged between 18 and 47 years $(M=21.4, S D=5.23)$ were recruited via opportunity sample. All participants spoke Swedish as their first language and reported normal (or corrected-tonormal) vision and normal hearing. None had taken part in Experiment 1. Participants were randomly, and equally, assigned to one of the between-participants groups: fluent (Times New Roman) or disfluent (Haettenschweiler) text (see Figure 2). Thus, 38 participants were assigned to the Times New Roman font condition and 38 participants were assigned to the Haettenschweiler font condition. This study was approved by the Uppsala regional ethical review board (REPN 2011/338).

Noise conditions. The same sounds as in the normal-speech condition of Experiment 1 were used. As in Experiment 1, these were presented via stereo headphones at approximately $69 \mathrm{~dB}$ (LAeq) — as measured via an artificial ear—via a Dell Latitude E6430 laptop PC.

Focal task. The office-based task was identical to that used in Experiment 1 . The only difference was that the font was changed to Haettenschweiler for the disfluent-text group. Haettenschweiler font was chosen on the basis of the results of prior studies within our laboratory (e.g., Halin, 2016; Halin, Marsh, Haga et al., 2014; Halin, Marsh, Hellman et al., 2014) and extant research that adopted this font to induce disfluency (e.g., Diemand-Yauman, Oppeheimer, \& Vaughan, 2011; Hernandez \& Preston, 2013; Seufert, Wagner, \& Westphal, 2017). Disfluency refers to a "subjective experience of difficulty associated with cognitive operation” (Diemand-Yauman et al., 2011, p. 111). Previous work provides empirical support that Haettenschweiler is indeed more difficult to read than Times New Roman. It has been 
found that participants rated reading paragraphs written in Haettenschweiler font as more

difficult and more taxing than paragraphs written in Times New Roman (Halin, Marsh, Haga

et al., 2014; Halin, Marsh, Hellman et al., 2014; Seufert et al., 2017). Seufert and colleagues

(2017) showed that perceived quality and legibility of Haettenschweiler further declined

when text contrast was reduced (e.g., using a grey instead of a black font).

\section{Fluent text}

\begin{tabular}{|c|c|c|c|c|c|c|c|c|c|}
\hline & & 20 & & 20 & 08 & & 009 & 20 & 10 \\
\hline & & Salary & Employees & Salary & Employees & Salary & Employees & Salary & Employees \\
\hline Teachers & Men & 25600 & 26500 & 26600 & 25900 & 27500 & 25400 & 27800 & 24800 \\
\hline & Women & 25200 & 29100 & 26100 & 28800 & 27100 & 29000 & 27300 & 29000 \\
\hline & Total & 25400 & 55600 & 26400 & 54700 & 27300 & 54400 & 27500 & 53800 \\
\hline Police officers & Men & 27800 & 11000 & 28800 & 11400 & 29600 & 11800 & 29500 & 12300 \\
\hline & Women & 26200 & 3700 & 27000 & 4000 & 28100 & 4200 & 27900 & 4700 \\
\hline & Total & 27400 & 14700 & 28300 & 15400 & 29200 & 16000 & 29100 & 17000 \\
\hline Carpenters & Men & 24800 & 89700 & 26000 & 89800 & 26600 & 85700 & 26800 & 89500 \\
\hline & Women & 18500 & 1500 & 22600 & 1400 & 22200 & 1400 & 21700 & 1200 \\
\hline & Total & 24000 & 91200 & 25900 & 91200 & 26100 & 87100 & 26300 & 90700 \\
\hline Train drivers & Men & 26100 & 4700 & 28500 & 4300 & 29200 & 3600 & 29700 & 4200 \\
\hline & Women & 25500 & 520 & 26600 & 610 & 27900 & 500 & 28900 & 660 \\
\hline & Total & 26000 & 5220 & 28300 & 4910 & 29000 & 4100 & 29600 & 4860 \\
\hline
\end{tabular}

How much was the mean salary for a female police officer in 2008 ?

2. How much was the salary for a male teacher in the year that $\mathbf{4 2 0 0}$ women worked as police officers?

3. Which occupations have the highest number of employees in total in the year 2010 compared with 2007 ?

\begin{tabular}{|c|c|c|c|c|c|c|c|c|c|}
\hline \multirow{3}{*}{ Teachers } & \multirow[b]{3}{*}{ Men } & \multicolumn{2}{|c|}{2007} & \multicolumn{2}{|c|}{2008} & \multicolumn{2}{|c|}{2009} & \multicolumn{2}{|c|}{2010} \\
\hline & & Salary & Employees & Salary & Employees & Salary & Employees & Salary & Employees \\
\hline & & 25600 & 26500 & 26600 & 25900 & 27500 & 25400 & 27800 & 24800 \\
\hline & Women & 25200 & 29100 & 26100 & 28800 & 27100 & 29000 & 27300 & 29000 \\
\hline & Iotal & 25400 & 55600 & 26400 & 54700 & 27300 & 54400 & 27500 & 53800 \\
\hline Police officers & Men & 27800 & 11000 & 28800 & 11400 & 29600 & 11800 & 28500 & 12300 \\
\hline & Women & 26200 & 3700 & 27000 & 4000 & 28100 & 4200 & 27900 & 4700 \\
\hline & Iotal & 27400 & 14700 & 28300 & 15400 & 29200 & 16000 & 29100 & 17000 \\
\hline Carpenters & Men & 24800 & 89700 & 26000 & 89800 & 26600 & 85700 & 26800 & 89500 \\
\hline & Women & 18500 & 1500 & 22600 & 1400 & 22200 & 1400 & 21700 & 1200 \\
\hline & Iotal & 24000 & 91200 & 25900 & 91200 & 26100 & 87100 & 26300 & 90700 \\
\hline Irain drivers & Men & 26100 & 4700 & 28500 & 4300 & 29200 & 3600 & 29700 & 4200 \\
\hline & Women & 25500 & 520 & 26600 & 610 & 27900 & 500 & 28900 & 660 \\
\hline & Iotal & 26000 & 5220 & 28300 & 4910 & 29000 & 4100 & 29600 & 4860 \\
\hline
\end{tabular}

\section{Disfluent text}

1. How much was the mean salary for a female police officer in 2008 ?

2 How much was the salary for a male teacher in the year that 4200 women worked as police officers?

3. Which occupations have the highest number of employees in total in the year 2010 compared with $2007 ?$

Figure 2. Example of problems and the fonts employed in the fluent text (Times New Roman) and disfluent text (Haettenschweiler) conditions of Experiment 2. 
Another crucial finding from previous research is that although participants find

Haettenschweiler font more difficult and demanding, their performance at baseline (i.e., in a quiet environment) with this disfluent font is comparable to their performance at baseline with fluent font (Times New Roman). This finding has been observed across three different studies, one focused on proofreading (Halin, Marsh, Haga et al., 2014; Experiment 1) and two on text memory (Halin, Marsh, Hellman et al., 2014; Halin, 2016). Moreover, all of these studies demonstrate that Haettenschweiler protects performance against distraction (performance being better with Haettenschweiler than with Times New Roman for background speech conditions, and no effect of background speech within the Haettenschweiler condition). An additional reason why we adopted Haettenschweiler as the disfluent font in this experiment was that it has been shown not to induce fatigue, at least over the short-term (e.g., up to 20 minutes; Halin, 2016).

Design. The study employed a mixed design with one between-participants factor: Disfluency (fluent text [Times New Roman] vs. disfluent text [Haettenschweiler]), and one within-participant factor: Sound Condition (quiet, halfalogue, and dialogue). The dependent variable was number of problems correctly solved.

Procedure. This was identical to Experiment 1.

\section{Results}

As in Experiment 1, a preliminary analysis including Order (of sound conditions) revealed no main effect of Order, nor were there any interactions with Order. Therefore, this factor was omitted from the following analysis. As can be seen in Figure 3, the main effect of Sound Condition was significant, $F(2,148)=8.26, M S E=4.90, p<.001, \eta^{2} \mathrm{p}=.1$. However, there was no between-participants main effect of Disfluency, $F(1,74)=.71, M S E=35.90, p$ $=.404, \eta^{2}{ }_{p}=.009$. Crucially, however, the interaction between Sound Condition and Disfluency was also significant, $F(2,148)=8.18, M S E=4.90, p=.002, \eta_{\mathrm{p}}^{2}=.1$. This 
interaction arose because, as illustrated in Figure 3, the effect of Sound Condition was significant with fluent text, $F(2,74)=18.06, M S E=4.35, p<.001, \eta^{2}{ }_{p}=.328$, but not with disfluent text $(F<1)$. Further investigation of the impact of Sound Condition with fluent text revealed that problem solving performance was significantly impaired by halfalogues compared to dialogues or quiet $(p s<.001)$, whereas no difference was found between dialogues and quiet $(p=.311)$.

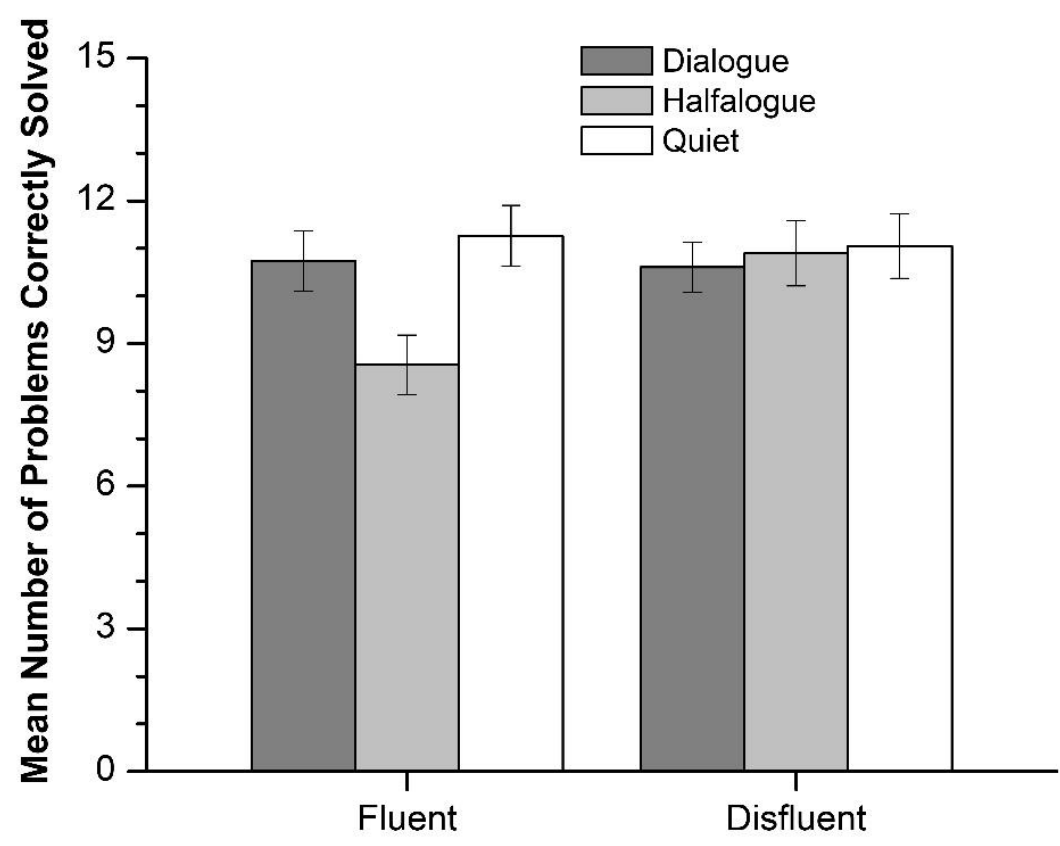

Text

Figure 3. Mean number of problems correctly solved across the three sound conditions for fluent and disfluent text conditions. Error bars represent the standard error of the mean.

The results of Experiment 2 reinforce the position that the halfalogue effect is driven by attentional capture (e.g., Hughes et al., 2013) as opposed to competition-for-action (e.g., Marsh et al., 2008, 2009): Making text within the search task disfluent—which we argue increases task-engagement (Sörqvist \& Marsh, 2015)—removed the disruptive effect of the halfalogue observed with meaningful speech in Experiment 1 and with the fluent font in Experiment 2. This suggests that the halfalogue effect can be tempered by top-down cognitive control (cf. Halin, Marsh, Haga et al., 2014; Halin, Marsh, Hellman et al., 2014; 
Hughes et al., 2013; Marsh et al., 2015) and that a simple manipulation of changing font-type

to enhance task-engagement could protect against the disruption produced by half conversations within office and scholastic settings.

The results of the current study combined with previous results (e.g., Halin, Marsh, Haga et al., 2014; Halin, Marsh, Hellman et al., 2014; Hughes et al., 2013) demonstrate that manipulations designed to increase perceptual demand (or load) reduce or even eradicate the effect of distraction while having little, or no impact, on task performance. It is assumed that a compensatory upward shift in focal task-engagement (i.e. concentration) is triggered under high perceptual load conditions in order to help shield against distractor processing (Linnell \& Caparos, 2013; Sörqvist, Dahlström, Karlsson, \& Rönnberg, 2016; Sörqvist \& Marsh, 2015).

How is distraction modulated by task-engagement? Higher task-engagement would appear to have two different effects (Sörqvist \& Marsh, 2015). First, it may potentiate a blocking mechanism whereby attention is prevented from being captured by auditory events such as onsets of unexpected sounds or, as argued in the current study, semantic un(predictability)/need-to-listen. Therefore, higher task-engagement promotes a more steadfast locus of attention (Hughes et al., 2013). Second, increased task-engagement may attenuate the processing of background sound by constraining auditory-sensory gating (Marsh \& Campbell, 2016; Sörqvist et al., 2016; Sörqvist, Stenfelt, \& Rönnberg, 2012), thereby preventing irrelevant speech from reaching semantic levels of analysis within the cognitive system (Marsh \& Campbell, 2016; Marsh et al., 2015). Both of these possibilities could explain why high task-engagement removed the halfalogue effect in Experiment 2.

The blocking view (Hughes et al., 2013) supposes that the meaning of the speech would be processed in the high task-engagement condition but that attentional switches to the auditory material are prevented due to the engendering of greater task-engagement in 
response to increased encoding load. Alternatively, the gating mechanism supposes that high task-engagement attenuates perceptual processing to the extent that the meaning of background speech is not registered. Previous research (e.g., Hughes et al., 2013) has favored the blocking view over the sensory gating view since the same increase in task-engagement attenuated the disruption produced by an unexpected deviant sound but had no effect on the disruption produced by acoustically changing sound (the so-called changing-state effect). This finding is at odds with the expectation — on the sensory gating approach — that the changing-state effect should also be reduced, or even eliminated.

An alternative explanation of the benefit of disfluency against distraction is offered by "Load Theory" (e.g., Lavie \& DeFockert, 2003). On this view, the presence of the disfluent font might be expected to deplete a bespoke attentional resource for perceptual processing. As a consequence, fewer resources are left to spill over and process distracters thereby ameliorating distraction. The notion that distraction by background sound can be attenuated by increased perceptual load would fit neatly with the finding that perceptual load reduces internal distractions via task-unrelated thoughts (Forster \& Lavie, 2009). However, according to the definitions of perceptual and sensory load by proponents of the Load Theory, perceptual disfluency would appear to align more with sensory load. Indeed, Lavie and DeFockert (2003) manipulate sensory load by reducing the size and contrast of a target, similar to manipulations of font disfluency (e.g., Faber et al., 2017). In contrast, perceptual load is manipulated by adding more distractors to a display. Lavie and DeFockert (2003) report that distraction is increased with higher sensory load, a result that is at odds with the results of Experiment 2, wherein the disfluent font attenuated distraction.

\section{General Discussion}

Our aims in the current study were threefold. First, we wanted to investigate the theoretical basis of the halfalogue effect to determine whether is it caused by acoustic 
unexpectedness or by semantic (un)predictability. Second, we wanted to address whether the with the task. This second aim was directed at applied concerns relating to potential ways to shield against telephone distraction. Third, and directly relevant to the previous aim, we wished to make use of ecologically valid tasks and materials that were representative of the kinds of typical activities that office workers might undertake in a busy open-plan environment within which employees sit in close proximity and are exposed to neighbouring telephone conversations.

\section{Implications for Theory}

In terms of our aim to advance theory, the results of Experiment 1 clearly demonstrate that the halfalogue effect is attributable to semantic (un)predictability rather than acoustic unexpectedness since the effect was only evident when semantic properties were discernable within the task-irrelevant speech. The general idea, then, is that semantic (un)predictability produces attentional capture. This proposal is also supported by the results of Experiment 2, where higher task-engagement—achieved by making text more difficult to read—which reduces attentional capture (e.g., Hughes et al., 2013), served to eliminate the halfalogue effect.

In sum, our results demonstrate that the halfalogue effect is a specific attentional capture effect that is caused by meaningful sound of some inherent interest to the individual. If it can be assumed that the halfalogue produces disruption because it causes a temporary shift of attention away from the focal task — due to a "need-to-listen" - then it can be considered a task interruption (e.g., Hodgetts \& Jones, 2006), that is, attention is shifted from the focal task to the source of interruption and thereafter must be reallocated to the focal task to resume it post-interruption. In order to deal effectively with an interruption, participants must suspend a task goal and then later resume it after the interruption. According to the 
goal-activation model (Altmann \& Trafton, 2002), interruptions result in the decay of task goals, which increases as a function of the time spent on the interruption task. Suspendedgoal reactivation is a time-consuming (Altmann \& Trafton, 2007) and attention-demanding (Hodgetts, Vachon, \& Tremblay, 2014) process, which can disrupt performance when resuming the primary task. Shifts of attention to background speech such as a halfalogue, despite often fleeting, may result in goal decay. Indeed, interruptions in the order of a few seconds (e.g., an average of $2.8 \mathrm{~s}$ ) can disrupt the train of thought, thereby resulting in missed steps in the focal task (Altmann, Trafton, \& Hambrick, 2014).

Yet, based on the current results, it is not clear whether the halfalogue effect can be interpreted, either fully or in partly, in terms of interruption cost. In particular, we note that it is difficult to determine whether interruptions induced by a need-to-listen were frequent and long enough to produce sufficient primary-goal decay to incur an interruption cost. In the same vein, it is also difficult to determine the extent to which the halfalogue was processed, hence how demanding the interruption was. It is well established that an interruption that is more cognitively demanding (i.e., that requires the activation of competing goals) tends to be more disruptive due to an increase in the level of interference at resumption (Hodgetts \& Jones, 2006). The fact that more disruption was found with meaningful than meaningless halfalogues in Experiment 1 could be accounted for by meaningful (normal) speech being more demanding to process than meaningless (rotated) speech, hence inducing a larger interruption cost.

However, this "interruption hypothesis" as an explanation of the halfalogue effect has no provision to account for the abolition of the effect observed in Experiment 2 when primary-task information was harder to read. In effect, the perceptibility of task-relevant material is not expected to alter the level of activation of primary-task goals nor the 
complexity of the primary task. Although plausible, an interpretation of the halfalogue effect

\section{Implications for Telephony and the Office Environment}

In relation to our applied aims, Experiments 1 and 2 have collectively improved our understanding of the nature of the halfalogue effect in a way that facilitates the genesis of suggestions that could reduce its disruptive impact. We acknowledge, however, that, some of the more obvious proposals for reducing the impact of halfalogues on task performance could be considered impractical. For example, one suggestion that follows on directly from the current study is that the subjective annoyance and behavioral distraction of halfalogues could be diminished if both sides of the conversation were audible (Monk, Fellas, \& Ley, 2004). To achieve this, the speaker could adjust their handset settings such that the individual exposed to the input can hear the other person speaking. However, this comes with the loss of privacy for the conversation (Kim \& de Dear, 2013). Moreover, within a populated office adding more voices can have the effect of increasing the intensity of the background speech. Although, a raft of previous findings have demonstrated that the disruption produced by background speech of visually-based tasks is independent of sound intensity (Colle, 1980; Jones, Miles, \& Page, 1990), noisy environments decrease acoustic satisfaction and increase subjective workload of the individuals exposed to the background sound (Keus van de Poll et al., 2015). Examining whether the distraction produced by a halfalogue can be reduced by adjusting telephony equipment such that both sides of the conversation are heard is clearly a priority for future research. Subsequent research should endeavor to investigate what effect this intentional addition of noise has on the office environment or its occupants as well as whether it can reduce disruption produced via the halfalogue.

Another target for further work is to establish whether the halfalogue effect extends beyond the objective distraction that arose from a personal conversation, since it is possible 
that work-related conversations may differ from personal conversations in their potency to distract performance. Indeed, subjective ratings suggest that personal conversations are likely to attract attention and are therefore distracting (Norman \& Bennett, 2014). Although we did not compare the impact of work-related conversations to that of personal conversations, at the very least the foregoing implies that conversation that is nonessential to work-related issues should be curtailed.

Generally, the implications of our current understanding of the halfalogue effect as offered by the current study suggest that the effect of the halfalogue could be tempered or eliminated in two ways that can be addressed separately, or in combination in future work.

\section{Reducing semantic processing of potentially distracting background speech.}

Since our study has determined that semantic processing underpins the increased distraction produced by a halfalogue, any sound, speech or otherwise, that masks the semantic content and thus the intelligibility of such sound could restore performance to levels observed in quiet conditions (Keus van de Poll et al., 2015). If semantic processing of background speech is reduced by decreasing its intelligibility, then the "need to listen" driving the halfalogue effect should be greatly diminished. For the reduction of distraction by meaningful halfalogues, one might therefore advocate the use of masking sound in the working environment to combat the potential negative impact of background speech on such cognitive tasks. Such masking sound could be based on multiple voices (e.g., Ebissou, Chevret, \& Parizet, 2013; Hellbrück \& Kilcher, 1993; Jones \& Macken, 1995; Kilcher \& Hellbrück, 1993; Kittel, Wenzke, Drotleff, \& Liebl, 2013; Klatte \& Hellbrück, 1993; Perham \& Banbury, 2011; Vachon, Winkler, Lavandier, \& Hughes, 2017) or derive from a broadband noise-emitting masking system (e.g., Haapakangas et al., 2011).

Indeed, previous work has demonstrated that reducing the intelligibility of speech via masking reduces the disruption that it produces to tasks underpinned by semantic processes 
(Keus van de Poll, Ljung, Odelius, \& Sörqvist, 2014; Keus van de Poll et al., 2015; see also

Haka et al., 2009; Jahncke et al., 2013; Loewen \& Suedfeld, 1992; Venetjoki, Kaarlela-

Tuomaala, Keskinen, \& Hongisto, 2007). Since adding multiple voices reduces speech intelligibility as effectively as a broadband noise-emitting device (e.g., Keus van de Poll et al., 2015), especially within reverberant work environments (Vachon, Winkler et al., 2017), it is possible that companies could save on investment in these systems by simply rearranging offices. However, one possible side effect of increasing the ambient noise within the environment - through adding a mask — is that people may adjust the intensity of their voices such that the intelligibility of their speech is undiminished (the Lombard effect; Lombard, 1911).

One further way in which individuals could limit their exposure to background sound would be by them playing their own preference of sound through headphones connected to iPods or computers at work stations. These preferred sounds could also mask the external sounds, thereby reducing their intelligibility. However, if the preference is music, there is a growing literature that task-irrelevant background music can impair performance on visuallybased tasks, regardless of an individual's preference for the musical piece (see, e.g., Perham \& Currie, 2014: Perham \& Vizard, 2011; Threadgold, Marsh, \& Ball, 2018). Similarly, it should be noted that the halfalogue effect might be expected to occur much less in call center settings. Herein the worker may attend to a conversation over headphones that could, like listening to preferred sounds over headphones, effectively mask speech sounds within their surroundings.

While the research here appears to advocate the use of masking, whether or not this is successful will clearly depend on whether the individual is required to listen to another individual (e.g., co-worker) speak within the environment. This is because the masking sound could impair listening comprehension. Moreover, the potential to reduce distraction must be 
offset by subjective ratings that typically demonstrate that individuals have low acceptance ratings for continuous noise as a mask (Schlittmeier \& Hellbrïck, 2009). In this respect, the accepted use of a mask may be contingent on the use of less artificial sounds that not only reduce behavioral distraction but also have a less detrimental impact on subjective ratings of acoustic satisfaction such as spring water (Haapakangas et al., 2011) and nature sounds (Jahncke, Björkeholm, Marsh, Odelius \& Sörqvist, 2015).

2. Increasing task-engagement. As shown in Experiment 2 of our current study, one way in which one could potentially circumnavigate the negative effects of masking solutions to telephone distraction is simply to change the text of the focal task material to a more disfluent, difficult-to-read font. When working with word documents and spreadsheets, this manipulation is fairly easy and inexpensive to achieve and does not materially affect performance on the task within the control conditions (e.g., quiet; see also Halin, 2016; Halin, Marsh, Haga et al., 2014; Halin, Marsh, Hellman et al., 2014). As has been suggested elsewhere (e.g., Halin, Marsh, Haga et al., 2014; Halin, Marsh, Hellman et al., 2014; Hughes et al., 2013; Marsh et al., 2015) rendering the text difficult to read arguably has the consequence of increasing engagement with the task. However, the literature on the disfluency effect is mixed as to whether the use of a disfluent font impacts, or not, upon the execution of a task. While some seminal studies suggested that disfluent fonts were beneficial to learning and comprehension (e.g., Diemand-Yauman et al., 2011) and non-intuitive problem solving tasks (Alter, Oppenheimer, Epley, \& Eyre, 2007), subsequent work, including direct replications of previous studies, has cast doubt on the beneficial effect of disfluency on task performance (e.g., Meyer et al., 2015; Thompson et al., 2013). Since we found that disfluency had no effect on task performance in the baseline, quiet condition of Experiment 2, we cannot recommend disfluency in general. However, the disappearance of the halfalogue effect in Experiment 2 supports the idea that disfluency effects may be 
contingent on particular task conditions (Kühl \& Eitel, 2016; Alter, Oppenheimer, \& Epley,

2013). In the current study, the disfluency effect is manifest as a shielding against distraction via halfalogue speech (see also Ball et al., 2018; Halin, Marsh, Haga et al., 2014; Halin, Marsh, Hellman et al., 2014; Hughes et al., 2013; Marsh et al., 2015).

The lack of a direct effect of perceptual disfluency on cognitive task performance is consistent with a recent report showing that perceptual disfluency (presenting text in gray Comic Sans font, relative to black Arial font) reduced incidences of internal distractionsmind wandering - during the reading of text in a comprehension task without having a direct effect on text comprehension scores (Faber et al., 2017). Akin to our task-engagement explanation of the elimination of the halfalogue effect in the disfluent font condition, the authors propose that disfluency influences comprehension through enhancing attention (thereby reducing mind wandering). Therefore, Experiment 2 suggests that the use of a disfluent font could be beneficial under some contexts, namely in environments characterized by the presences of extraneous noise.

However, we must be cautious not to mislead through conveying the message that the difficulty of worker's task should be increased to reduce the distraction they experience from work-irrelevant phone conversations. Our inference (see also Faber et al., 2017) is that perceptual disfluency increases task-engagement and that it is this task-engagement that modulates top-down control over distraction. Increasing the perceptual disfluency of task material is only one manipulation that can increase task-engagement. Forster and Lavie (2009) propose that task-engagement encompasses a number of other factors that are associated with attention, including motivation, interest, arousal level and engagement of processes within thought and working memory.

Consistent with this latter idea, Seli, Schacter, Risko, and Smilek (2017) found that increased motivation reduced mind wandering during a sustained attention task. Similarly, 
Engleman, Damaraju, Padmala, and Pessoa (2009) found that incentives could prevent taskirrelevant sound from disrupting ongoing task performance. In addition, Ball et al. (2018, Experiment 2) showed that the disruption produced by background speech to the solution of word-associate problems was reduced when participants were given an incentive for good task performance. Moreover, Ball et al.'s finding conceptually replicated their initial experiment, which found that presenting the word-associate problems in a disfluent font (Haettenschweiler) compared to a fluent font (Arial) reduced distraction by the same background speech. Crucially, neither incentive (Experiment 2), nor disfluency (Experiment 1) led to superior performance in quiet conditions.

The similarity between the effects of motivation and disfluency on distraction shielding supports the parsimonious view that task-engagement can be modulated by both extrinsic cues, such as incentives for good task performance, and intrinsic cues, such as perceptual disfluency and trait capacity for task-engagement (or working memory capacity; Hughes et al., 2013; Marsh, Vachon, \& Sörqvist, 2017; Sörqvist, 2010). Increasing taskengagement through increasing motivation (e.g., by offering incentives for good performance), enhancing interest, and triggering the engagement of working memory processes such as top-down control (e.g., via the presentation of tasks in a disfluent font) are all potential interventions that could help to shield performance from distraction via background halfalogue speech.

In relation to perceptual disfluency, further research is required to understand the degree of perceptual difficulty (and the stimulus characteristics) in relation to the task material that is (are) necessary to observe the shielding effects of background speech on task performance. Moreover, it is important to address whether the same manipulations confer a benefit for all participants, or whether there are systematic and measureable differences between participants concerning the likelihood that they will benefit (Halin, Marsh, Hellman 
et al., 2014). In addition to this requirement to explore the potential boundary conditions for the shielding effect, it is important to identify its time course. Outstanding questions include whether the positive effect of working with a distinct font constitutes only a short-term benefit, and whether there are any negative consequences of increasing perceptual difficulty in relation to increased fatigue and workload, over the longer-term. Answers to these questions may help adjudicate whether the manipulation of font fluency offers a means by which distraction can be attenuated and eliminated, especially in situations wherein other solutions are impractical, such as reducing background speech to below hearing thresholds.

In relation to the recommendations made in the foregoing, a general note of caution should be voiced. While some desirable difficulties can be introduced to improve performance, or at least shield performance against distraction, undesirable difficulties can sometimes be unwittingly introduced. Currently there is limited guidance from theory or empirical work that could help identify an optimal level of difficulty/disfluency. Furthermore, such an optimal level, if achievable, may differ as a function of specific situations such as task characteristics or an individual's trait capacity for cognitive control (Hughes et al., 2013). Therefore, when outlining practical implications and suggesting practical recommendations one must be cautious to take into account both contextual factors (the environment and task difficulty) and dispositional factors.

\section{Conclusion}

Background telephone conversations are distracting due to their semantic unpredictability. The apparent "need-to-listen" is pervasive: the half conversation captures attention from cognitive tasks, thereby impairing performance. Due to the large number of telephones used within the office environment, halfalogues are very difficult to escape and undoubtedly have substantial adverse effects on the productivity, motivation, satisfaction and wellbeing of office workers. Strategies that may mitigate against the distraction produced by 
a halfalogue include masking the intelligibility of the speech and the designation of private levels within the office environment making the comprehension of conversation between coworkers within the office difficult. Two non-mutually exclusive ways in which distractionat least by a meaningful halfalogue — can be reduced is through reducing the semantic processing of the halfalogue and the promotion of task-engagement. The latter may be achieved by increasing motivation, interest and arousal level and by catalyzing working memory processes (Forster \& Lavie, 2009). In the current study, task-engagement was increased by making the text disfluent, thereby rendering it more difficult to read. However, it is likely that other manipulations of task-engagement such as incentive for good task performance can have similar distraction-shielding effects (Ball et al., 2018; Seli et al., 2017). One must weigh up the potential benefits of reducing the "need-to-listen" against potential communicative problems within the office, the loss of privacy, negative subjective evaluations of the soundscape of the office environment, and in the case of promoting focal task-engagement through a disfluency manipulation, any long-term consequences of reading a difficult-to-read font (e.g., potential eyestrain). Clearly, whether masking and taskengagement manipulations would be useful in protecting against the disruptive effect of a halfalogue depends on the ecology of the workplace. This must be considered prior to the design of solutions and such solutions must be readily evaluated before their effectiveness and acceptability can be determined. 


\section{References}

Alter, A. L., Oppenheimer, D. M., \& Epley, N. (2013). Disfluency prompts analytic thinking-But not always greater accuracy: Response to Thompson et al. (2013). Cognition, 128, 252-255.

Alter, A. L., Oppenheimer, D. M., Epley, N., \& Eyre, R. N. (2007). Overcoming intuition: Metacognitive difficulty activates analytic reasoning. Journal of Experimental Psychology: General, 136, 569-576.

Altmann, E. M., Trafton, J. G., \& Hambrick, D. Z. (2014). Momentary interruptions can derail the train of thought. Journal of Experimental Psychology: General, 143, 215-226.

Altmann, E. M., \& Trafton, J. G. (2002). Memory for goals: An activation-based model. Cognitive Science, 26, 39-83.

Altmann, E. M., \& Trafton, J. G. (2007). Timecourse of recovery from task interruption: Data and a model. Psychonomic Bulletin \& Review, 14, 1079-1084.

Avanta Serviced Office Group: Office Noise Costing UK Economy Millions. (n.d.). Retrieved August 29, 2015. Available: http://www.officingtoday.com/2015/02/avanta$\underline{\text { serviced-office-group-office-noise-costing-uk-economy-millions/ }}$

Babisch, W. (2003). Stress hormones in the research on cardiovascular effects of noise. Noise $\&$ Health, 5, 1-11.

Ball, L. J., Threadgold, E., Solowiej, A., \& Marsh, J. E. (2018). Can intrinsic and extrinsic metacognitive cues shield against distraction in problem solving? Journal of Cognition.

Beaman, C. P. (2005). Auditory distraction from low-intensity noise: A review of the consequences for learning and workplace environments. Applied Cognitive Psychology, $19,1041-1064$.

Bjork, R. A., Dunlosky, J., \& Kornell, N. (2013). Self-regulated learning: Beliefs, techniques, and illusions. Annual Review of Psychology, 64, 417-444. 
Buetti, S., \& Lleras, A. (2016). Distractibility as a function of engagement, not task difficulty: Evidence from a new oculomotor capture paradigm. Journal of Experimental Psychology: General, 145, 1382-1405.

Colle, H. A. (1980). Auditory encoding in visual short-term recall: Effects of noise intensity and spatial location. Journal of Verbal Learning \& Verbal Behavior, 19, 722-735.

Diemand-Yauman, C., Oppenheimer, D. M., \& Vaughan, E. B. (2011). Fortune favors the bold and the italicized: Effects of disfluency on educational outcomes. Cognition, 118, 111-115.

Ebissou, A., Chevret, P., \& Parizet, E. (2013). Work performance and mental workload in multiple talker environments. In International Congress on Acoustics 2013, December 2012, Montréal, Canada, No. 4pNSa8.

Eimer, M., Nattkemper, D., Schröger, E., \& Prinz, W. (1996). Involuntary attention. Handbook of Perception and Action, 3, 155-184.

Eggemeier, F. T., Crabtree, M. S., \& LaPointe, P. A. (1983, October). The effect of delayed report on subjective ratings of mental workload. In Proceedings of the Human Factors and Ergonomics Society Annual Meeting (Vol. 27, No. 2, pp. 139-143). SAGE Publications.

Ellermeier, W., \& Zimmer, K. (1997) Individual differences in susceptibility to the irrelevant speech effect. Journal of the Acoustical Society of America, 102, 2191-2199.

Emberson, L. L., Lupyan, G., Goldstein, M. H., \& Spivey, M. J. (2010). Overheard cellphone conversations: When less speech is more distracting. Psychological Science, 21, 1383-1388.

Engelmann, J. B., Damaraju, E., Padmala, S., \& Pessoa, L. (2009). Combined effects of attention and motivation on visual task performance: transient and sustained motivational effects. Frontiers in Human Neuroscience, 3, 1-17. 
Escera, C., Yago, E., Corral, M. J., Corbera, S., \& Nuñez, M. I. (2003). Attention capture by auditory significant stimuli: semantic analysis follows attention switching. European Journal of Neuroscience, 18, 2408-2412. doi:10.1046/j.1460-9568.2003.02937.x

Evans, G. W., \& Johnson, D. (2000). Stress and open-office noise. Journal of Applied Psychology, 85, 779-783.

Evans, G. W., \& Stecker, R. (2004). Motivational consequences of environmental stress. Journal of Environmental Psychology, 24, 143-165.

Faber, M., Mills, C., Kopp, K., \& D’mello, D. (2017). The effect of disfluency on mind wandering during text comprehension. Psychonomic Bulletin \& Review, 24, 914-919.

Forster, S., \& Lavie, N. (2009). Harnessing the wandering mind: The role of perceptual load. Cognition, 111, 345-355.

Galván, V. V., Vessal, R. S., \& Golley, M. T. (2013). The effects of cell phone conversations on the attention and memory of bystanders. PLOS ONE, 8, e58579.

Haapakangas, A., Kankkunen, E., Hongisto, V., Virjonen, P., Oliva, D., \& Keskinen, E. (2011). Effects of five speech masking sounds on performance and acoustic satisfaction: Implications for open-plan offices. Acta Acustica United with Acustica, 97, 641-655.

Haka, M., Haapakangas, A., Keränen, J., Hakala, J., Keskinen, E., \& Hongisto, V. (2009). Performance effects and subjective disturbance of speech in acoustically different office types: A laboratory experiment. Indoor Air, 19, 454-467.

Halin, N. (2016). Distracted while reading? Changing to a hard-to-read font shields against the effects of environmental noise and speech on text memory. Frontiers in Psychology, 7, 1-6. 
Halin, N., Marsh, J. E., Haga, A., Holmgren, M., \& Sörqvist, P. (2014). Effects of speech on proofreading: Can task-engagement manipulations shield against distraction? Journal of Experimental Psychology: Applied, 20, 69-80.

Halin, N., Marsh, J. E., Hellman, A., Hellström, I., \& Sörqvist, P. (2014). A shield against distraction. Journal of Applied Research in Memory \& Cognition, 3, 31-36.

Halin, N., Marsh, J. E., \& Sörqvist, P. (2015). Central load reduces peripheral processing: Evidence from incidental memory of background speech. Scandinavian Journal of Psychology, 56, 607-612.

Hellbrück, J., \& Kilcher, H. (1993). Effects on mental tasks induced by noise recorded and presented via an artificial head system. In M. Vallet (Ed.), Noise \& man '93 (pp. 315322). Arcueil, France: Institut National de Recherche sur les Transports et Leur Sécurite.

Hughes, R. W. (2014). Auditory distraction: A duplexmechanism account. PsyCh Journal, $3,30-41$.

Hughes, R. W., Hurlstone, M. J., Marsh, J. E., Vachon, F., \& Jones, D. M. (2013). Cognitive control of auditory distraction: Impact of task difficulty, foreknowledge, and working memory capacity support duplex-mechanism account. Journal of Experimental Psychology: Human Perception \& Performance, 39, 539-553.

Hughes, R., Vachon, F., \& Jones, D. M. (2005). Auditory attentional capture during serial recall: Violations at encoding of an algorithm-based neural model? Journal of Experimental Psychology: Learning, Memory, \& Cognition. 31, 736-749.

Hughes, R. W., Vachon, F., \& Jones, D. M. (2007). Disruption of short-term memory by changing and deviant sounds: Support for a duplex-mechanism account of auditory distraction. Journal of Experimental Psychology: Learning, Memory, \& Cognition, 33, 1050-1061. 
Hodgetts, H. M., \& Jones, D. M. (2006). Interruption of the Tower of London task: Support for a goal activation approach. Journal of Experimental Psychology: General, 135, 103-115.

Hodgetts, H. M., Vachon, F., \& Tremblay, S. (2014). Background sound impairs interruption recovery in dynamic task situations: Procedural conflict? Applied Cognitive Psychology, 28, 10-21.

Jahncke, H., Björkeholm, P., Marsh, J. E., Odelius, J., \& Sörqvist, S. (2016). Office noise: Can headphones and masking sound attenuate distraction by background speech? Work, $55,505-513$.

Jahncke, H., \& Halin, N. (2012). Performance, fatigue and stress in open-plan offices: the effects of noise and restoration on hearing impaired and normal hearing individuals. Noise \& Health, 14, 260-272.

Jahncke, H., Hongisto, V., \& Virjonen P. (2013). Cognitive performance during irrelevant speech: effects of speech intelligibility and office-task characteristics. Applied Acoustics, 74, 307-316.

Jiang, B., Liebl, A., Leistner, P., Yang, J. (2012). Sound masking performance of timereversed masker processed from the target speech. Acta Acustica united with Acustica, $98,135-141$.

Jones, D. M., \& Macken, W. J. (1995). Auditory babble and cognitive efficiency: Role of number of voices and their location. Journal of Experimental Psychology: Applied, 1, 216-226.

Jones, D., Miles, C., \& Page, J. (1990). Disruption of proofreading by irrelevant speech: Effects of attention, arousal or memory? Applied Cognitive Psychology, 4, 89-108.

Keus van de Poll, M., Carsson, J., Marsh, J. E., Ljung, R., Odelius, J., Schlittmeier, S. J., Sundin, G., \& Sörqvist, S. (2015). Unmasking the effects of masking on performance: 
The potential of multiple-voice masking. The Journal of the Acoustical Society of America, 138, 807-816.

Keus van de Poll, M., Ljung, R., Odelius, J., \& Sörqvist, P. (2014). Disruption of writing by background speech: the role of transmission index. Applied Acoustics, 81, 15-18.

Kilcher, H., \& Hellbrück, J. (1993). The irrelevant speech effect: Is binaural processing relevant or irrelevant? In M. Vallet (Ed.), Noise \& man '93 (pp. 323-328). Arcueil, France: Institut National de Recherche sur les Transports et Leur Sécurite.

Kim, J., \& de Dear, R. (2013). Workspace satisfaction: The privacy-communication trade-off in open-plan offices. Journal of Environmental Psychology, 36, 18-26.

Kittel, M., Wenzke, E., Drotleff, H., \& Liebl, A. (2013). Auditory babble as a masker of disruptive speech. $42^{\text {nd }}$ International Congress and Exhibition on Noise Control Engineering, Innsbruck, Austria.

Kjellberg, A., Landstrom, U., Tesarz, M., Soderberg, L., \& Akerlund, E. (1996). The effects of nonphysical noise characteristics, ongoing task and noise sensitivity on annoyance and distraction due to noise at work. Journal of Environmental Psychology, 16, 123136

Klatte, M., \& Hellbrück, J. (1993) Der “irrelevant speech effect”: Wirkungen von hintergrundschall auf das arbeitsgedächtnis. Zeitschrift für Lärmbekämpfung, 40, 91-98.

Kühl, T., \& Eitel, A. (2016). Effects of disfluency on cognitive and metacognitive processes and outcomes. Metacognition \& Learning, 11, 1-13.

Lavie, N., \& De Fockert, J. W. (2003). Contrasting effects of sensory limits and capacity limits in visual selective attention. Attention, Perception, \& Psychophysics, 65, 202212.

Linnell, K. J., \& Caparos, S. (2013). Perceptual load and early selection: An effect of attentional engagement? Frontiers in Psychology, 4, 498. 
Loewen, L. J., \& Suedfeld, P. (1992). Cognitive and arousal effects of masking office noise. Environment \& Behavior, 24, 381-395.

Lombard, E. (1911). Le signe de l'elevation de la voix. Ann. Maladies Oreille, Larynx, Nez, Pharynx, 37, 101-119.

Mak, C. M., \& Lui, Y. P. (2012). The effect of sound on office productivity. Building Services Engineering Research \& Technology, 33, 339-345.

Marsh, J. E., \& Campbell, T. A. (2016). Processing complex sounds passing through the rostral brainstem: The new early filter model. Frontiers in Neuroscience, 10, 136.

Marsh, J. E., Hughes, R. W., \& Jones, D. M. (2008). Auditory distraction in semantic memory: A process-based approach. Journal of Memory \& Language, 58, 682-700.

Marsh, J. E., Hughes, R. W., \& Jones, D. M. (2009). Interference by process, not content, determines semantic auditory distraction. Cognition, 110, 23-38.

Marsh, J. E., Patel, K., Labonté, K., Threadgold, E., Skelton, F. C., Fodarella, C., Thorley, R., Battersby, K. L., Frowd, C. D., Ball, L. J., \& Vachon, F. (2017). Chatting in the face of the eyewitness: The impact of extraneous cell-phone conversation on memory for a perpetrator. Canadian Journal of Experimental Psychology, 71, 183-190.

Marsh, J. E., Röer, J., Bell, R., \& Buchner, A. (2014). Predictability and distraction: Does the neural model represent post-categorical features? $\mathrm{PsyCH}, 3,58-71$.

Marsh, J. E., Sörqvist, P., \& Hughes, R. W. (2015). Dynamic cognitive control of irrelevant sound: Increased task-engagement attenuates semantic auditory distraction. Journal of Experimental Psychology: Human Perception \& Performance, 41, 1462-1474.

Marsh, J. E., Vachon, F., \& Sörqvist, P. (2017). Increased distractibility in schizotypy: Independent of individual differences in working memory capacity? Quarterly Journal of Experimental Psychology, 70, 565-578.

Meyer, A., Frederick, S., Burnham, T. C., Guevara Pinto, J. D., Boyer, T. W., Ball, L. J., ... \& 
Schuldt, J. P. (2015). Disfluent fonts don't help people solve math problems. Journal of Experimental Psychology: General, 144, 2, e16.

Monk, A., Carroll, J., Parker, S., \& Blythe, M. (2004). Why are mobile phones annoying? Behaviour \& Information Technology, 23, 33-41.

Monk, A., Fellas, E., \& Ley, E. (2004). Hearing only one side of normal and mobile phone conversations. Behaviour \& Information Technology, 23, 301-305.

Norman, B., \& Bennett, D. (2014). Are mobile phone conversations always so annoying? The ‘need-to-listen' effect revisited. Behavior \& Information Technology, 33, 1294-1305.

Park, M. S., Kohlrausch, A. G., \& van Leest, A. J. (2013). Irrelevant speech effect under stationary and adaptive masking conditions. Journal of the Acoustical Society of America, 134, 1970-1981.

Parmentier, F. B. R., Elford, G., Escera, C., Andrés, P., \& San Miguel, I. (2008). The cognitive locus of distraction by acoustic novelty in the cross-modal oddball task. Cognition, 106, 408-432.

Parmentier, F. B. R., Elsley, J. V., Andrés, P., \& Barceló, F. (2011). Why are auditory novels distracting? Contrasting the roles of novelty, violation of expectation and stimulus change. Cognition, 119, 374-380.

Parmentier, F. B. R., \& Kefauver, M. (2015). The semantic aftermath of distraction by deviant sounds: Crosstalk interference is mediated by the predictability of semantic congruency. Brain Research, 1626, 247-257.

Perham, N., \& Banbury, S. P. (2011). Do practical signal-to-noise ratios reduce the irrelevant sound effect? Cognitive Technology, 16, 1-10.

Perham, N., \& Banbury, S. P. (2012). The role of rehearsal in a novel call center-type task. Noise \& Health, 14, 1-5. 
Perham, N., Banbury, S. P., \& Jones, D. M. (2007). Do realistic reverberation times reduce auditory distraction? Applied Cognitive Psychology, 21, 839-847.

Perham, N., \& Currie, H. (2014). Does listening to preferred music improve reading comprehension performance? Applied Cognitive Psychology, 28, 279-284.

Perham, N. \& Sykora, M. (2012). Disliked music can be better for performance than liked music. Applied Cognitive Psychology, 26, 550-555.

Perham, N., \& Vizard, J. (2011). Can preference for background music mediate the irrelevant sound effect? Applied Cognitive Psychology, 25, 625-631.

Schlittmeier, S. J., \& Hellbrück, J. (2009). Background music as noise abatement in openplan offices: A laboratory study on performance effects and subjective preferences. Applied Cognitive Psychology, 23, 684-697.

Schlittmeier, S., Hellbrück, J., Thaden, R., \& Vorländer, M. (2008). The impact of background speech varying in intelligibility: Effects on cognitive performance and perceived disturbance. Ergonomics, 51, 719-736.

Schröger, E. (1997). On the detection of auditory deviants: A pre-attentive activation model. Psychophysiology, 34, 245-257.

Scott, S. K., Rosen, S., Beaman, C. P., Davis, J. P., \& Wise, R. J. S. (2009). The neural processing of masked speech: Evidence for different mechanisms in the left and right temporal lobes. Journal of the Acoustical Society of America, 125, 1737-1743.

Seli, P., Schacter, D. L., Risko, E. F., \& Smilek, D. (2017). Increasing participant motivation reduces rates of intentional and unintentional mind wandering. Psychological Research.

Seufert, T., Wagner, F., \& Westphal, J. (2017). The effects of different levels of disfluency on learning outcomes and cognitive load. Instructional Science, 45, 221-238.

Sörqvist, P. (2010). High working memory capacity attenuates the deviation effect but not the 
changing-state effect: Further support for the duplex-mechanism account of auditory distraction. Memory \& Cognition, 38, 651-658.

Sörqvist, P., Dahlström, Ö, Karlsson, T., \& Rönnberg, J. (2016). Concentration: The neural underpinnings of how cognitive load shields against distraction. Frontiers in Human Neuroscience, 10, 221.

Sörqvist, P., \& Marsh, J. E. (2015). How concentration shields against distraction. Current Directions in Psychological Science, 24, 267-272.

Sörqvist, P., Marsh, J. E., \& Jahncke, H. (2010). Hemispheric asymmetries in auditory distraction. Brain \& Cognition, 74, 79-87.

Sörqvist, P., Stenfelt, S., \& Rönnberg, J. (2012). Working memory capacity and visualverbal cognitive load modulate auditory-sensory gating in the brainstem: Toward a unified view of attention. Journal of Cognitive Neuroscience, 24, 2147-2154.

Stavrinos, D., Byington, K. W., \& Schwebel, D. C. (2009). Effect of cell phone conversation of pediatric pedestrian injury risk. Pediatrics, 123 , e179-185.

Strayer, D. L., \& Johnston, W. A. (2001). Driven to distraction: Dual-task studies of driving and conversing on a cellular telephone. Psychological Science, 12, 462-466.

Sundstrom, E., Town, J. P., Rice, R. W., Osborn, D. P., \& Brill, M. (1994). Office noise, satisfaction, and performance. Environment \& Behavior, 26, 195-222.

Szalma, J. L., \& Hancock, P. A. (2011). Noise effects on human performance: A metaanalytic synthesis. Psychological Bulletin, 137, 682-707.

Thompson, V. A. (2010). Toward a metacognitive dual process theory of conditional reasoning. Cognition and Conditionals: Probability and Logic in Human Thinking, 335-354. 
Thompson, V. A., Turner, J. A. P., Pennycook, G., Ball, L. J., Brack, H., Ophir, Y., \& Ackerman, R. (2013). The role of answer fluency and perceptual fluency as metacognitive cues for initiating analytic thinking. Cognition, 128, 237-251.

Threadgold, E., Marsh, J. E., \& Ball, L. J. (2017). Background music stints creativity: Evidence from the compound remote associates task. Manuscript submitted for publication.

Toivanen, S. (2015). Framtidens arbetsplatser. Att utveckla hållbara och friska kontor. [Workplaces of the future. Developing sustainable and healthy offices]. Stockholm: Vitt grafiska.

Vachon, F., Hughes, R. W., \& Jones, D. M. (2012). Broken expectations: Violation of expectancies, not novelty, captures auditory attention. Journal of Experimental Psychology: Learning, Memory, \& Cognition, 38, 164-177.

Vachon, F., Labonté, K., \& Marsh, J. E. (2017). Attentional capture by deviant sounds: A noncontingent form of auditory distraction? Journal of Experimental Psychology: Learning, Memory, and Cognition, 43, 622-634.

Vachon, F., Winder, E., Lavandier, M., \& Hughes, R. W. (2017). The bigger the better and the more the merrier? Realistic office reverberation levels abolish cognitive distraction by multiple-voice speech. Proceedings of the 12th ICBEN International Congress on Noise as a Public Health Problem. International Commission on Biological Effects of Noise (ICBEN).

Venetjoki, N., Kaarela-Toumaala, A., Keskinen, E., \& Hongisto, V. (2007). The effect of speech and speech intelligibility on task performance. Ergonomics, 49, 1068-1091. Weinstein, N. D. (1974). Effects of noise on intellectual performance. Journal of Applied Psychology, 59, 548-554. 
Winkler I., Denham S. L., \& Nelken, I. (2009). Modeling the auditory scene: predictive regularity representations and perceptual objects. Trends in Cognitive Science, 13, 532540.

Young, H., \& Berry, G. (1979). The impact of environment on the productivity attitudes of intellectually challenged office workers. Human Factors, 21, 399-407. 


\section{Author note}

John E. Marsh, University of Gävle, Gävle, Sweden and the University of Central Lancashire, Preston, UK. Robert Ljung, Helena Jahncke and Douglas MacCutcheon and François Vachon, University of Gävle, Gävle, Sweden. Florian Pausch, Institute of Technical Acoustics, RWTH Aachen University, Aachen, Germany. Linden J. Ball, University of Central Lancashire, Preston, UK. François Vachon is also at the École de psychologie, Université Laval, Québec, Canada. John Marsh's contribution to this article was supported by a grant from the Swedish Research Council (2015-01116) awarded to Patrik Sörqvist and to John Marsh. François Vachon received financial support from the Natural Sciences and Engineering Research Council of Canada (NSERC) in the form of a grant (418623-2013). We would like to thank Elina Pekkola and Marijke Keus van de Poll for help with the data collection. 